\title{
Photonics Explorer Workshop
}

\section{Amrita Prasad, Nathalie Debaes}

Amrita Prasad, Nathalie Debaes, "Photonics Explorer Workshop," Proc. SPIE 9289, 12th Education and Training in Optics and Photonics Conference, 92892C (17 July 2014); doi: 10.1117/12.2070729

SPIE Event: 12th Education and Training in Optics and Photonics Conference, SPIE. 2013, Porto, Portugal 


\title{
Photonics Explorer Workshop
}

\author{
Amrita Prasad, Nathalie Debaes \\ Vrije Universiteit Brussel, Pleinlaan 2, 1050 Brussels, Belgium
}

\begin{abstract}
The Photonics Explorer is an intra-curricular educational kit developed in a European project with a pan-European collaboration of over 35 teachers and science education professors. Unlike conventional educational outreach kits, the Photonics Explorer is specifically designed to integrate seamlessly in school curricula and enhance and complement the teaching and learning of science and optics in the classroom. The kit equips teachers with class sets of experimental components, provided within a supporting didactic framework and is designed for lower and upper secondary students (12-18 years). The kit is provided completely free of charge to teachers in conjunction with teacher training courses.

The workshop will provide an overview of the Photonics Explorer intra-curricular kit and give teachers the opportunity to work hands-on with the material and didactic content of two modules, 'Light Signals' (lower secondary) and 'Diffraction and Interference'(upper secondary).

We also aim to receive feedback regarding the content, components and didactic framework from teachers from nonEuropean countries, to understand the relevance of the kit for their teaching and the ability for such a kit to integrate into non-EU curricula.
\end{abstract}

Keywords: K12, education, intra-curricular, kit, hands-on, photonics, workshop

\section{INTRODUCTION}

The Photonics Explorer is an intra-curricular kit which has been specifically designed to integrate seamlessly into European secondary school science curricula and enhance and complement the teaching and learning of photonics within the classroom. The kit has been specifically designed to complement existing European secondary school science curricula and therefore support teachers while engaging students. Each kit contains a class set of experimental components provided within a supporting didactic framework based on guided Inquiry-Based Learning (IBL) techniques. The content is designed for lower (12-14 years) and upper (16-18 years) secondary students. The kit is a result of a panEuropean collaboration of over 35 teachers, experts in pedagogy, scientists at universities, industry as well as the extended European photonics community.

\section{PHOTONICS EXPLORER KIT}

\subsection{Experimental Components and Didactic Framework}

Each kit consists of a class set of experimental components, sufficient for a class of 25-30 students to work in groups of 2-3. The components have been specifically designed to be safely used by students within the classroom. The components are robust, versatile and durable and can be used in a range of experiments. The components in each kit are:

- 10 aluminium mirrors $(7 \times 7 \mathrm{~cm})$

- 10 colour filter sets $(7 \times 4 \mathrm{~cm})$ including red, green, blue, cyan, magenta and yellow

- 10 LED modules with red, green and blue LEDs

- 10 sets of robust plastic lenses with the focal lengths $30 \mathrm{~mm},-30 \mathrm{~mm}$, and $150 \mathrm{~mm}$

- 20 polarisers $(7 \times 5 \mathrm{~cm})$

- 5 m polymer optical fibre

- 10 eyesafe Lasers

- 10 diffraction gratings

- 10 foils with slit and double slit for optical diffraction experiments

12th Education and Training in Optics and Photonics Conference, edited by

Manuel F. P. C. Martins Costa, Mourad Zghal, Proc. of SPIE Vol. 9289, 92892C

(C) 2014 SPIE, OSA, IEEE, ICO · doi: 10.1117/12.2070729

Proc. of SPIE Vol. 9289 92892C-1 


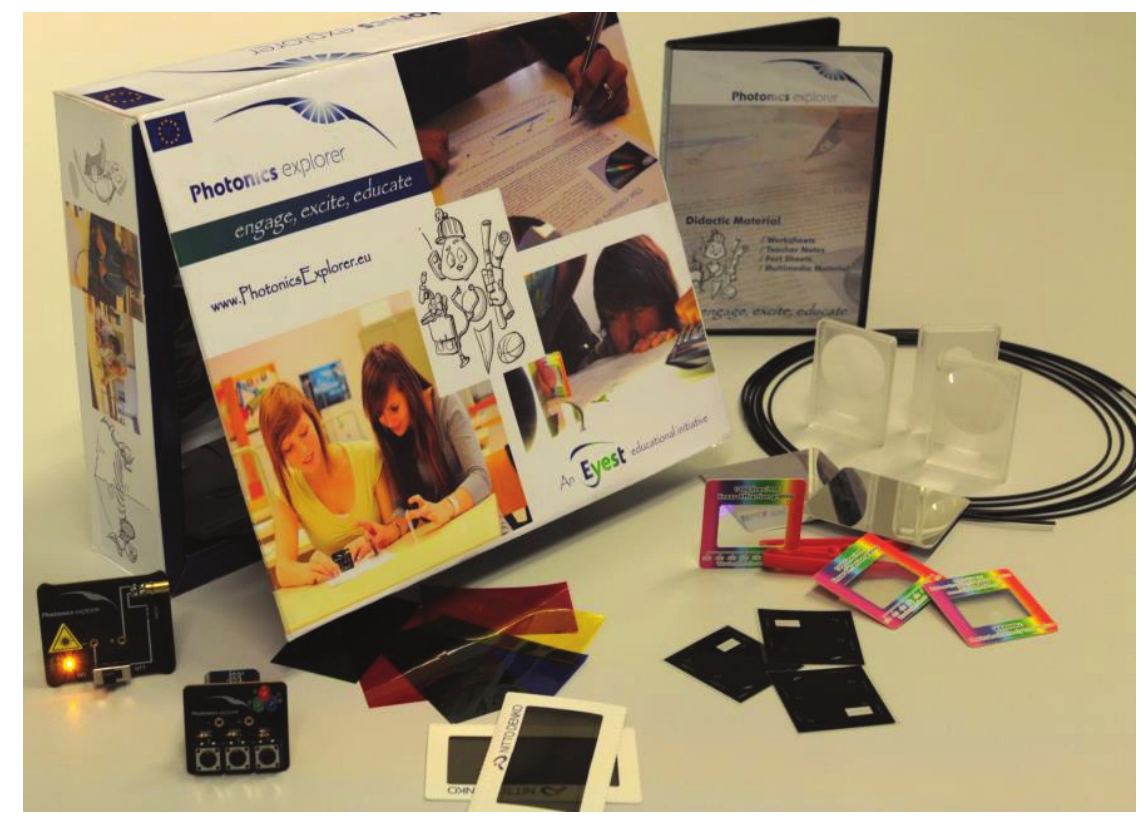

Figure 1: The Photonics Explorer kit

The didactic content has been developed to satisfy the diverse educational systems and teaching environments across Europe and to give students the opportunity to really work as scientists and engineers in the classroom. The kit is designed in a modular structure with 8 stand-alone modules; 4 for lower secondary and 4 for upper secondary levels. The topics of the modules are as follows:

The modules for Lower secondary level (12-14 years)

- Light signals - the properties of light and its use in telecommunication

- Colours - colour perception, additive and subtractive colour mixing

- Lenses and telescopes - refraction and imaging

- Eye and vision - comparison between human eyes and digital cameras, accommodation in the eye

The modules for Upper secondary level (16-18 years)

- Making light - comparing different light sources, laser

- Polarisation - applications in displays and life sciences

- Diffraction and interference - diffraction on a slit, spectrometry

- A scientist's job - encouraging esp. young women to pursue careers in science and engineering

Each module consists of worksheets and factsheets for the students, a comprehensive teacher guide and, where relevant, supporting multimedia material, like pictures and videos that further help to illustrate the concepts. The modular structure allows teachers the flexibility to include and adapt the modules into their individual classroom situations. Each topic is always linked to current technologies thus making the science relevant in the context of students' daily lives.

Worksheets are designed so that students can work in groups to design their own experimental setups, come up with a hypothesis and test it to arrive at a reasonable conclusion. They then discuss the observed phenomenon, its origin/cause and how such an effect could be useful. They then directly relate this optical effect to current technologies encountered in their daily life. 


\section{WORKSHOP OVERVIEW}

The Photonics Explorer workshop aims to provide teachers with an overview of the content and context of the kit and the principles of inquiry based learning on which the material is based. In particular, teachers will be given an overview of the development process, an explanation of each module and two modules will be explained in detail with the accompanying didactics.

The 'Light Signals' module is designed for lower secondary level (12-14 years) and consists of worksheets for 3 lessons, factsheets and a teacher guide. Students discuss a hypothetical situation of ' 3 villages in a valley' that want an efficient communication system. They are given a set of criteria that need to be satisfied and thus they learn to come up with solutions, much like in a real engineering situation. Students then encode the alphabet using red, green and blue LEDs and communicate a 10-letter word across the classroom using an optical fibre.

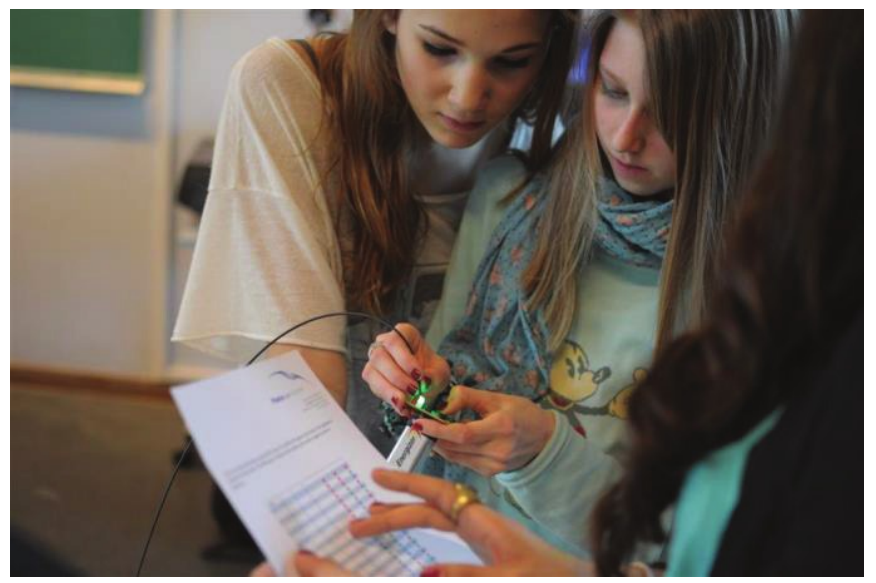

Figure 2 Students communicate a word using LEDs through an optical fibre

The module on 'Diffraction and Interference' is designed for upper secondary students (16-18 years) and consists of worksheets for 3 lessons as well as factsheets, teacher guide and a video.

In this module, students build their own 'Spectrometer' to resolve and measure the wavelength of the different colours in the spectrum of an energy saving light bulb. This leads to the understanding of differences between an energy-saving bulb and a 'normal' incandescent light bulb. Students are also encouraged to discuss the far-reaching applications of spectrometry. Further, they perform experiments to see double and single slit diffraction patterns and even measure the width of their own hair. Thus they realize that the application of diffraction is in measuring extremely small (micro scale) structures. They are also introduced to the discovery of the structure of the DNA using diffraction.

Teachers can peruse all the components and didactic content of the kit and interact with the developer team to provide their feedback and present their questions. Furthermore, they can also provide information about the options for distribution of the Photonics Explorer in their own country and educational systems.

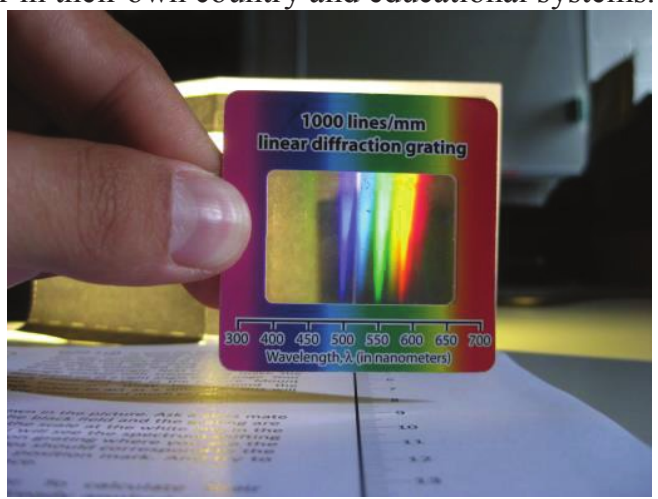

Figure 3 Colours of the spectrum of an energy saving light bulb seen through a diffraction grating provided in the kit 